\title{
The use of tree level vs. stand level data in forest planning calculations - does it really matter?
}

\author{
Marc PAlahi $^{1 *}$, Timo PUKKald $^{2,3}$, Antoni Trasobares $^{3}$ \\ ${ }^{1}$ Centre Tecnológic Forestal de Catalunya, Passeig Lluis Companys, 23, 08010, Barcelona, Spain \\ ${ }^{2}$ University of Joensuu, Faculty of Forestry, PO Box 111, 80101 Joensuu, Finland \\ ${ }^{3}$ Foreco Technologies, Av. Diagonal 416, Estudio 2, Barcelona 08037, Spain
}

(Received 23 December 2006; accepted 28 March 2007)

\begin{abstract}
This study examined how the type of compartment inventory data affects the outcome of forest planning calculations. The inventory data alternatives were tree level data vs. a set of stand characteristics. When stand characteristics were used the diameter distribution of trees was predicted from the stand variables. For this, prediction models for the parameters of the diameter distribution of stand basal area were developed for seven main tree species in Catalonia. An optimisation approach was used to find the coefficients of the parameters models. The predicted diameter distribution was either scaled to yield the measured total stand basal area, or calibrated with the help of more than one stand characteristics. Individual tree data were used as a reference method to which the stand level data and the alternative ways to derive the diameter distributions were compared. The methods were compared in terms of calculated inventory results, growth predictions and treatment prescriptions (harvest removals per compartment) for the province of Lleida in Catalonia. The results showed that tree- and stand-level inventory data give very similar results. Calibration of the predicted diameter distribution improved the accuracy of forest planning calculations. When stand basal area, number of trees per hectare and basal-area-weighted median diameter were used to calibrate the diameter distributions the results were rather close to those based on tree level inventory data.
\end{abstract}

diameter distribution models / calibration / forest planning

Résumé - L'utilisation des données au niveau arbre par rapport au niveau peuplement dans les calculs de planification en forêt - Est-ce réellement important? Ce travail analyse comment le type de données d'inventaire affecte les calculs de planification et de gestion forestières. Les données d'inventaire testées étaient soient des données concernant les arbres, soit des caractéristiques générales des peuplements. Lors de la mise en œuvre de caractéristiques de peuplement, la distribution des diamètres des arbres était prédite à partir des variables de peuplement. Pour cela, des modèles prédictifs de distribution de diamètres à partir de la surface terrière ont été développés pour sept espèces d'arbres de Catalogne. Une approche par optimisation a été utilisée pour trouver les coefficients des modèles. La distribution des diamètres prédite a été soit directement rapportée à la surface terrière totale, soit calibrée avec plusieurs caractéristiques du peuplement. Des données par arbre ont été utilisées comme référence pour une comparaison des prédictions au niveau du peuplement et les solutions alternatives pour simuler la distribution des diamètres ont été analysées. Les méthodes ont été comparées en termes de résultats de calculs d'inventaire, de prédiction de croissance et de prescription de traitements sylvicoles (récoltes par compartiments) pour la province de Lleida en Catalogne. Les résultats montrent que les inventaires au niveau arbre et au niveau peuplement produisent des résultats très similaires. Une calibration de la distribution prédite des diamètres a amélioré la précision des calculs de planification forestière. Lorsque la surface terrière, le nombre d'arbre à l'hectare et la surface terrière pondérée par le diamètre médian étaient utilisés pour calibrer la distribution des diamètres les simulations produisaient des résultats très proches de ceux basés sur les données de l'inventaire par arbre.

modèles de distribution de diamètre / calibration / planification forestière

\section{INTRODUCTION}

In Catalonia, forest inventory is the most expensive task of forest management planning. Usually, many circular, concentric or relascope plots are placed within the compartment and the diameters of individual trees of the plots are measured and recorded. However, Palahí et al. [1] suggested that the use of calibrated diameter distribution models would allow the use of cheaper and more rapid forest inventory methods measuring only basal area $(G)$ and the number of trees per hectare $(N)$ in all stands, plus mean diameters in heterogeneous stands or in places where more accurate information is required. This

* Corresponding author: marc.palahi@ctfc.es method would facilitate smaller compartments to be demarcated, which are better in tactical and operational planning.

Catalonian forests are characterized by heterogeneous stands with a large variation in the spatial distribution of trees, tree species composition, number of stems per hectare, diameter distribution, and vertical structure of the stand. Efficient management planning tools for these forests require growth and yield functions that can produce detailed predictions of stand development under different management schedules. Several researchers have recently developed growth and yield models based on an individual tree approach (e.g.; [6-9, 15-18]) to address this need in Catalonia. However, when only stand-level inventory data are available, predicting the diameter distribution of trees is required in management planning 
which uses tree-wise growth models. When using predicted distribution, Maltamo [4] demonstrated that it is more accurate to predict the distributions of all main tree species of the stand separately rather than predicting one common distribution.

The aim of this study was to examine how the type of inventory data affects the outcome of forest planning calculations. Individual tree data were used as a reference method. Stand level data were used to predict the diameter distribution of trees, which was used in subsequent calculations. Different alternatives to calibrate predicted diameter distributions were also tested. The methods were compared in terms of calculated inventory results, growth predictions and treatment prescriptions (harvest removals) using the plots of the national forest inventory from the province of Lleida in Catalonia. Since there were no parameter models for the diameter distribution available for all species, new models were developed for those main tree species in Catalonia which lacked the models.

\section{MATERIALS AND METHODS}

\subsection{Modelling diameter distributions}

The modelling approach and data were the same as in the study of Palahí et al. [7], which developed diameter distributions models for Pinus sylvestris, Pinus nigra and Pinus halepensis. In the present study, additional models for seven other important tree species in Catalonia, as well as common models for all oaks, a model for all pines and a model for all species were developed. The common models were used for species that did not have a species-specific model. The modelling data were provided by the Spanish National Forest Inventory [2], which consisted of a systematic sample of permanent plots distributed on a square grid of $1 \mathrm{~km}$, with a 10-year remeasurement interval. From the inventory plots over the whole of Catalonia, all plots with at least five trees were selected. The distributions were fitted separately to all species of the plot that accounted for at least $15 \%$ of the number of trees. However, a maximum of three distributions per plot were fitted. If there were remaining trees, they were combined with the trees of the dominant species. The plots represented all age structures and degrees of mixture between species. Most of the stands were naturally regenerated. The sample plots were measured for the first time in 1989 and 1990. Data from this first measurement were used in modelling (see Tab. I). For more details on the sampling method and variables measured see Palahí et al. [10].

The two-parameter form of the truncated Weibull distribution was selected to model the basal area diameter distributions [10]. The probability density function of the two-parameter truncated Weibull distribution is:

$$
f(d)=\left\{\frac{c}{b}\left(\frac{d}{b}\right)^{c-1} \exp \left(\left(\frac{t}{b}\right)^{c}-\left(\frac{d}{b}\right)^{c}\right),(0 \leq d \geq \infty)\right.
$$

where $d$ is tree diameter $(\mathrm{cm}), b$ is the scale parameter, $c$ is the shape parameter and $t$ is a fixed truncation point $(7.5 \mathrm{~cm}$ in this study). The parameter prediction models were developed using the optimisation approach (method 6 in [1]). It minimises the following objective function:

$$
\min Z=\sum_{i=1}^{n} \sum_{j=1}^{n_{i}}\left(F_{i j}-\hat{F}_{i j}\right)^{2} / n_{i}
$$

where $F_{i j}=$ observed cumulative probability of tree $j$ in plot $i$; $\hat{F}_{i j}=$ $1-\exp \left\{\left(\frac{t}{b}\right)^{c}-\left(\frac{d_{i j}}{b}\right)^{c}\right\}$, i.e., the value of the cumulative distribution function evaluated at $d_{i j}$; and $d_{i j}=$ diameter of tree $j$ in plot $i$. The observed cumulative frequency of tree $j$ was calculated by dividing the number of trees smaller than or equal to $d_{i j}$ by the total number of trees on plot $i$. The optimised variables were the coefficients of the prediction models for Weibull parameters $b$ and $c$. These models had the following forms:

$$
\begin{gathered}
b=a_{0}+a_{1} \ln (N)+a_{2} \ln (G)+a_{3} \text { Ele }+a_{4} D q+a_{5} \ln (D q) \\
\ln (c)=a_{0}+a_{1} N+a_{2} G+a_{3} \text { Ele }+a_{4} D q+a_{5} \ln D q
\end{gathered}
$$

where $N$ is number of trees per hectare, $G$ is stand basal area $\left(\mathrm{m}^{2} \mathrm{ha}^{-1}\right)$, Ele is elevation $(\mathrm{m})$ and $D q$ is quadratic mean diameter $(\mathrm{cm} ; D q=\sqrt{(40000 / \pi \times G / N)})$. All predictors were not included in every model but only the significant ones.

It was assumed that two of the following stand characteristics were available; basal area $(G)$, number of stems per hectare $(N)$ or the quadratic mean diameter $(D q)$ [10]. Furthermore, the elevation of the plot was assumed to be available as a potential predictor in the parameter models.

\subsection{Testing of the use of stand-level inventory data}

All plots of the second NFI in the province of Lleida with more than 5 trees were used for examining the performance of stand level inventory data in combination with diameter distributions and different calibration variables. A total number of 2480 plots were used in the calculations. Each NFI plot represented 100 ha, which means that the calculations represented a forest area of 248000 ha (see Fig. 1). The only purpose of calculations was to test the effect of input data, i.e. they have no implications concerning forestry practice.

For each plot and separately for each species the following variables were calculated; number of trees $\mathrm{ha}^{-1}(N)$, stand basal area in $\mathrm{m}^{2} \mathrm{ha}^{-1}(G)$, non-weighted mean diameter in $\mathrm{cm}(D$, calculated as $\left.\sum d_{j} / N\right)$, basal area weighted mean diameter in $\mathrm{cm}(D g$, calculated as $\left.\sum g_{j} d_{j} / \sum g_{j}\right)$, median diameter in $\mathrm{cm}(D M)$ and basal area median diameter $(D g M) . D M$ is the diameter that divides the number of trees into two equal parts while $D g M$ divided stand basal area into two equal parts. Then, the following five methods were used to import the inventory data to the Spanish forest planning system for Catalonia, MONTE [13], which was used to conduct all calculations (T refers to tree-level inventory data and $\mathrm{S}$ to stand level data):

T: All measured trees in the plot were imported, i.e. empirical diameter distribution was used (reference method)

$\mathrm{S}$ : Number of trees per hectare $(N)$, stand basal area $(G)$, their transformation quadratic mean diameter $(D q)$ and elevation were used to predict the diameter distribution of the plot, i.e., parameters $b$ and $c$ of the Weibull distribution were predicted. This distribution was then used to calculate the frequencies of 1-cm diameter classes. One of the following variable combinations was used to scale (method 1) or calibrate (methods 2-4) the frequencies of diameter classes $(D g M=$ basal area median diameter, $D=$ nonweighted mean diameter, $D g=$ basal-area-weighted mean diameter, $D M=$ median diameter, $D g M=$ basal area median diameter):

1: $G$ (method 1, class frequencies scaled to match with the total basal area);

2: $G+N(\operatorname{method} 2)$; 
Table I. Mean, standard deviation (S.D.) and range of the main characteristics (including the $b$ and $c$ parameter estimates for the Weibull probability density function) of the study material. $G$ is stand basal area $\left(\mathrm{m}^{2} \mathrm{ha}^{-1}\right), N$ is number of trees ha ${ }^{-1}, D_{q}$ is quadratic mean diameter (cm), and Ele is elevation (m a.s.1.) of the plot.

\begin{tabular}{|c|c|c|c|c|c|c|c|}
\hline & & $N$ & $\bar{G}$ & $D q$ & Ele & $b$ & $c$ \\
\hline \multirow[t]{5}{*}{ P. sylvestris } & Mean & 549.37 & 14.57 & 19.96 & 10.86 & 24.69 & 4.66 \\
\hline & $n$ & 1834 & 1834 & 1834 & 1834 & 1834 & 1834 \\
\hline & S.D. & 432.68 & 9.53 & 6.12 & 3.75 & 8.13 & 2.23 \\
\hline & Min & 25.47 & 2.64 & 8.98 & 1.00 & 1.00 & 0.47 \\
\hline & Max & 3437.75 & 56.80 & 54.93 & 20.00 & 68.45 & 20.00 \\
\hline \multirow[t]{5}{*}{ P. uncinata } & Mean & 605.50 & 19.19 & 21.71 & 18.30 & 28.30 & 3.80 \\
\hline & $n$ & 546 & 546 & 546 & 546 & 546 & 546 \\
\hline & S.D. & 462.59 & 11.74 & 6.37 & 2.11 & 9.45 & 1.57 \\
\hline & Min & 39.61 & 3.17 & 8.91 & 1.00 & 1.00 & 0.46 \\
\hline & Max & 2864.79 & 61.41 & 48.01 & 24.00 & 80.00 & 9.75 \\
\hline \multirow[t]{5}{*}{ P. pinea } & Mean & 279.79 & 11.32 & 24.45 & 1.98 & 28.85 & 6.18 \\
\hline & $n$ & 350 & 350 & 350 & 350 & 350 & 350 \\
\hline & S.D. & 247.49 & 8.09 & 6.30 & 1.67 & 6.98 & 2.75 \\
\hline & Min & 34.52 & 2.81 & 10.11 & 0.00 & 2.23 & 0.64 \\
\hline & $\operatorname{Max}$ & 1955.84 & 57.13 & 50.98 & 8.00 & 54.21 & 20.00 \\
\hline \multirow[t]{5}{*}{ P. halepensis } & Mean & 463.20 & 9.85 & 18.05 & 3.74 & 21.75 & 4.88 \\
\hline & $n$ & 1569 & 1569 & 1569 & 1569 & 1569 & 1569 \\
\hline & S.D. & 347.20 & 5.66 & 5.09 & 1.96 & 6.47 & 2.56 \\
\hline & Min & 39.61 & 2.62 & 8.54 & 0.00 & 1.00 & 0.41 \\
\hline & Max & 2641.97 & 50.72 & 48.05 & 10.00 & 53.02 & 20.00 \\
\hline \multirow[t]{5}{*}{ P. nigra } & Mean & 639.16 & 12.04 & 17.07 & 6.76 & 20.69 & 4.53 \\
\hline & $n$ & 1221 & 1221 & 1221 & 1221 & 1221 & 1221 \\
\hline & S.D. & 506.85 & 7.46 & 5.06 & 2.29 & 6.89 & 2.42 \\
\hline & Min & 34.52 & 2.62 & 8.58 & 0.00 & 1.00 & 0.45 \\
\hline & Max & 4229.99 & 59.39 & 45.81 & 17.00 & 50.74 & 20.00 \\
\hline \multirow[t]{5}{*}{ A. alba } & Mean & 448.25 & 22.69 & 28.99 & 15.60 & 40.29 & 3.47 \\
\hline & $n$ & 133 & 133 & 133 & 133 & 133 & 133 \\
\hline & S.D. & 346.72 & 15.26 & 13.01 & 2.08 & 15.95 & 1.75 \\
\hline & Min & 30.56 & 3.52 & 9.45 & 7.00 & 4.27 & 0.72 \\
\hline & Max & 2228.17 & 72.43 & 96.68 & 20.00 & 80.00 & 13.12 \\
\hline \multirow[t]{5}{*}{ Q. ilex } & Mean & 855.16 & 9.70 & 12.62 & 5.53 & 13.85 & 4.17 \\
\hline & $n$ & 1607 & 1607 & 1607 & 1607 & 1607 & 1607 \\
\hline & S.D. & 559.79 & 5.92 & 3.11 & 2.83 & 5.35 & 2.75 \\
\hline & Min & 34.52 & 2.36 & 8.25 & 0.00 & 1.00 & 0.52 \\
\hline & Max & 3533.24 & 36.72 & 44.76 & 14.00 & 51.38 & 20.00 \\
\hline \multirow[t]{5}{*}{ Q. robur } & Mean & 458.92 & 11.02 & 19.20 & 2.21 & 23.85 & 4.24 \\
\hline & $n$ & 640 & 640 & 640 & 640 & 640 & 640 \\
\hline & S.D. & 341.86 & 6.26 & 5.86 & 1.42 & 7.89 & 2.00 \\
\hline & Min & 43.57 & 2.90 & 9.27 & 0.00 & 1.00 & 0.43 \\
\hline & $\operatorname{Max}$ & 2189.26 & 40.95 & 45.24 & 8.00 & 56.46 & 20.00 \\
\hline \multirow[t]{5}{*}{ F. sylvatica } & Mean & 586.73 & 15.10 & 21.01 & 10.99 & 27.89 & 3.58 \\
\hline & $n$ & 255 & 255 & 255 & 255 & 255 & 255 \\
\hline & S.D. & 467.28 & 9.45 & 8.64 & 2.66 & 14.44 & 1.75 \\
\hline & Min & 25.47 & 2.79 & 9.25 & 4.00 & 1.00 & 0.45 \\
\hline & Max & 2157.43 & 55.83 & 59.50 & 18.00 & 80.00 & 11.74 \\
\hline \multirow[t]{5}{*}{ All pines } & Mean & 540.95 & 13.06 & 19.1059 & 8.01 & 23.45 & 4.66 \\
\hline & $n$ & 5530 & 5530 & 5530 & 5530 & 5530 & 5530 \\
\hline & S.D. & 430.95 & 8.79 & 5.89 & 5.35 & 7.91 & 2.34 \\
\hline & Min & 25.47 & 2.62 & 8.54 & 0.00 & 1.00 & 0.41 \\
\hline & Max & 4229.99 & 61.41 & 54.93 & 24.00 & 80 & 20.00 \\
\hline \multirow[t]{5}{*}{ All oaks } & Mean & 695.15 & 9.78 & 14.88 & 5.29 & 17.34 & 4.21 \\
\hline & $n$ & 2971 & 2971 & 2971 & 2971 & 2971 & 2971 \\
\hline & S.D. & 519.23 & 5.89 & 5.51 & 3.21 & 8.52 & 2.61 \\
\hline & Min & 30.56 & 2.36 & 8.25 & 0.00 & 1.00 & 0.41 \\
\hline & Max & 3533.24 & 40.95 & 64.86 & 18.00 & 80.00 & 20.00 \\
\hline \multirow[t]{5}{*}{ All species } & Mean & 584.02 & 11.85 & 17.89 & 7.26 & 21.71 & 4.54 \\
\hline & $n$ & 9630 & 9630 & 9630 & 9630 & 9630 & 9630 \\
\hline & S.D. & 469.14 & 8.25 & 6.60 & 4.93 & 9.42 & 2.53 \\
\hline & Min & 25.47 & 2.36 & 7.98 & 0.00 & 1.00 & 0.41 \\
\hline & Max & 4229.99 & 72.43 & 96.68 & 24.00 & 80.00 & 20.00 \\
\hline
\end{tabular}




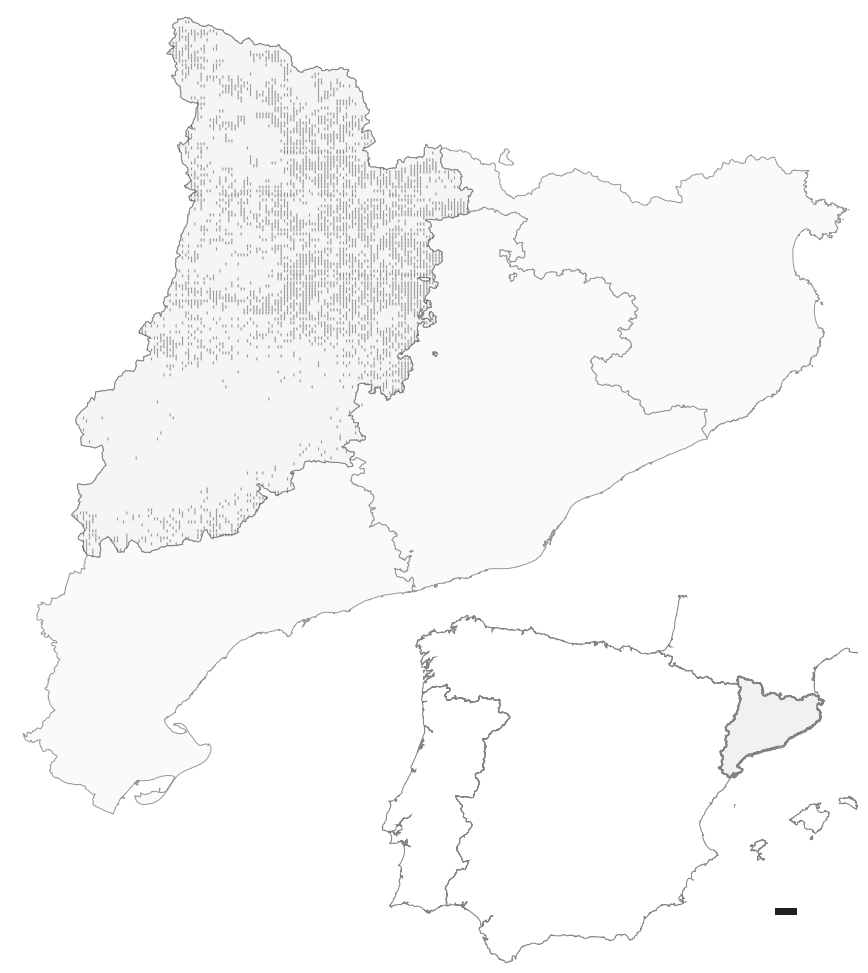

Figure 1. The location of Catalonia, the province of Lleida and the inventory plots which were used in the calculations of this study.

3: $G+N+D g M(\operatorname{method} 3)$;

4: $G+N+D+D g+D M+D g M(\operatorname{method} 4)$.

In cases 1 to 4 , the characteristics were imported by tree species and the parameters of the diameter distribution were predicted by tree species using the models developed in this study and in Palahí et al. [10]. The calibration technique used in methods $2-4$ is explained in detail in Palahí et al. [11]. The methods were compared in terms of calculated inventory results, growth predictions and treatment prescriptions (harvest removals per compartment). The calculations in MONTE are based on a set of representative trees, each tree being described by species, diameter, height, and number of trees per hectare. The representative trees can be the measured trees of inventory plots (method $\mathrm{T}$ above) of mid-point trees of diameter classes (method S). In this study, calculation of the inventory results used the individual-tree height models developed by Trasobares et al. $[17,18]$ and the stem volume functions published in the NFI [2], while calculating growth predictions (10-year predictions) used the models of Trasobares et al. [17, 18] for individual-tree diameter growth, tree height, ingrowth and tree survival. Finally, treatment prescriptions for all plots with the different data input methods were calculated by using combinatorial optimization tools available in the MONTE forest planning system [13]. For this, nine different treatment schedules representing uneven-aged forestry differing in the timing and intensity of the selection fellings were simulated for each plot over a 10-year period. The forest planning problem consisted of three objective variables; (1) annual value increment at the end of the 10-year period (to be maximized); (2) net income of the 10-year period (maximized) and (3) 10-year cutting target of exactly 5 million $\mathrm{m}^{3}$ (constraint). The cutting target of 5 million $\mathrm{m}^{3}$ resulted in plans in which the ending growing stock volume was nearly equal to the initial volume. The

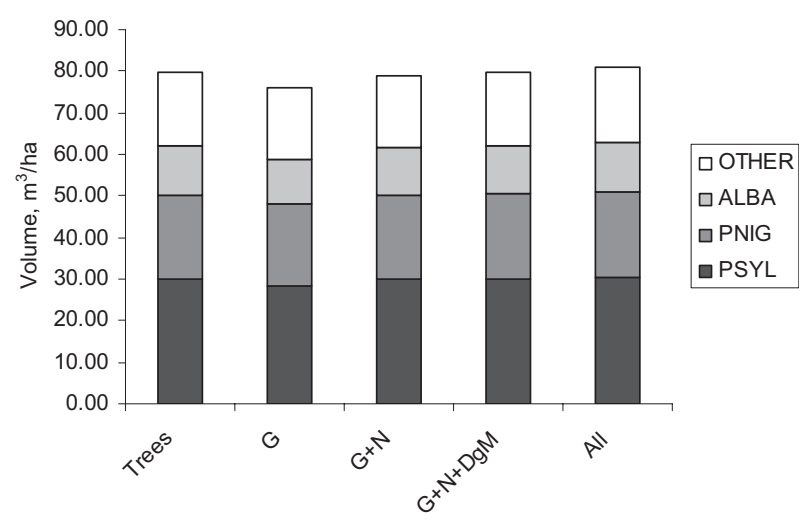

Figure 2. Mean standing volume estimated using the five different methods to use inventory data. The three most common species ( $\mathrm{Pi}$ nus sylvestris, $P$. nigra and Abies alba) are shown indivudually.

problem was solved using the tabu search heuristic [14]. The optimal solution included one schedule per plot and the corresponding harvested volume.

\section{RESULTS}

\subsection{Diameter distribution models}

The parameter models estimated by the optimisation approach are in Tables II and III. The $t$-values of all coefficients were high, mostly more than 10 . Only two of the main stand variables, $N, G$ and $D q$, were used simultaneously as predictors. Elevation $(E)$ was a significant predictor for $P$. sylvestris, $P$. uncinata and $P$. nigra, as well as for the models fitted for all pines and all species together.

\subsection{Current standing volume}

Using any combination of stand variables produced total volume estimates close to those based on tree-level data (Fig. 2). However, using only $G$ to scale the predicted diameter distribution underestimated the volume (Fig. 2). Figure 3 shows that the most accurate results were obtained when using all calibration variables (method 4). Furthermore, using $G+N+D g M$ produced more accurate results than when using $G$ or $G+N$. Among these two, the use of $G$ as a scaling variable produced less precise results than using $G+N$ (Fig. 3) and $G+N$ underestimated the current yield in about $1 \%$ of the plots (see Fig. 3).

Table IV shows the root mean square error (in $\mathrm{m}^{3} \mathrm{ha}^{-1}$ ) calculated for the current standing volume from the differences between estimates based on the different predicted diameter distributions and those based on the measured distribution (tree list). Using this criterion, method 3 had the best performance, although very similar to method 4 . Method 1 , which scaled the diameter distribution with $G$ produced a significantly higher RMSE. 
Table II. Regression coefficients of models for Weibull parameters $b$ and $\ln (c)$ for the main coniferous tree species in Catalonia.

\begin{tabular}{|c|c|c|c|c|c|c|c|}
\hline & P. sylvestris ${ }^{1}$ & P. uncinata & P. pinea & P. halepensis ${ }^{1}$ & P. nigra ${ }^{1}$ & All pines & A. alba \\
\hline \multicolumn{8}{|c|}{ Model for $b$} \\
\hline Const. & 64.771 & -1.226 & 2.861 & 0.072 & 64.344 & 65.918 & 6.465 \\
\hline $\ln (N)$ & -12.002 & - & - & - & -11.779 & -12.117 & - \\
\hline $\ln (G)$ & 12.475 & - & - & - & 12.292 & 12.104 & - \\
\hline Ele & 0.035 & - & - & - & - & 0.135 & - \\
\hline$D q$ & - & 1.307 & 1.021 & 1.180 & - & - & 1.269 \\
\hline $\ln (D q)$ & - & - & - & - & - & - & - \\
\hline \multicolumn{8}{|c|}{ Model for $\ln (c)$} \\
\hline Const. & 3.660 & 0.293 & -1.532 & 2.031 & 2.495 & -0.556 & 2.606 \\
\hline $\ln (N)$ & -0.396 & - & - & -0.123 & -0.192 & - & -0.293 \\
\hline$G$ & 0.020 & - & - & - & - & - & - \\
\hline Ele & -0.029 & -0.029 & - & - & -0.009 & -0.011 & - \\
\hline$D q$ & - & - & - & - & - & - & - \\
\hline $\ln (D q)$ & - & 0.370 & 0.985 & - & - & 0.615 & - \\
\hline
\end{tabular}

${ }^{1}$ Model of Palahi et al. [14].

Table III. Regression coefficients of models for Weibull parameters $b$ and $\ln (c)$ for the main broadleaves tree species in Catalonia.

\begin{tabular}{|c|c|c|c|c|c|}
\hline Parameters/Species & Q. ilex & Q. robur & All oaks & F. sylvatica & All species \\
\hline \multicolumn{6}{|l|}{ Model for $b$} \\
\hline Const. & -7.241 & -0.992 & -30.207 & -4.842 & -25.583 \\
\hline $\ln (N)$ & - & - & - & - & - \\
\hline $\ln (G)$ & - & - & - & - & - \\
\hline Ele & - & - & - & - & - \\
\hline$D q$ & 1.644 & 1.259 & 0.603 & 1.556 & 0.835 \\
\hline $\ln (D q)$ & - & - & 14.364 & - & 11.348 \\
\hline \multicolumn{6}{|l|}{ Model for $\ln (c)$} \\
\hline Const. & 2.639 & 2.985 & 1.987 & 2.205 & 1.999 \\
\hline $\ln (N)$ & -0.229 & -0.295 & -0.139 & -0.203 & -0.161 \\
\hline$G$ & - & - & - & - & 0.008 \\
\hline Ele & - & - & - & - & -0.004 \\
\hline$D q$ & - & - & - & - & - \\
\hline $\ln (D q)$ & - & - & - & - & - \\
\hline
\end{tabular}

\subsection{Growth predictions}

Ten-year growth predictions were produced using the 4 different methods to obtain diameter distributions in combination with the individual tree growth models of the MONTE planning system. Method 1 clearly overestimated the volume increment, while method 3 produced results closest to the reference method (Fig. 4). Figure 5 shows that at the plot level, growth predictions based on methods 3 and 4 were the most accurate, although slightly biased (they tend to overestimate the increments in $0.5-1 \%$ of the plots when compared to the increments predicted based on the measured trees). Figure 5 also shows that method 1 produced much less precise and rather biased predictions (overestimations). Method 2 followed method 1 in terms of inaccuracy.
Table IV shows that the root mean square error (in $\mathrm{m}^{3} \mathrm{ha}^{-1}$ ) calculated for the predicted 10-year volume increment was the lowest for method 4 followed closely by method 3. Again, method 1 produced the highest RMSE.

\subsection{Harvested volumes}

Figure 6 shows the harvested volume in the optimal plan in each plot calculated for each method used to estimate the initial diameter distribution. The more there are off-diagonal dots, the more the treatments are unequal. Dot located on $x$ and $y$ axes represent plots in which there is a cutting proposal with one input data alternative but no proposal with the other alternative. Dots near the diagonal are plots in which both the 

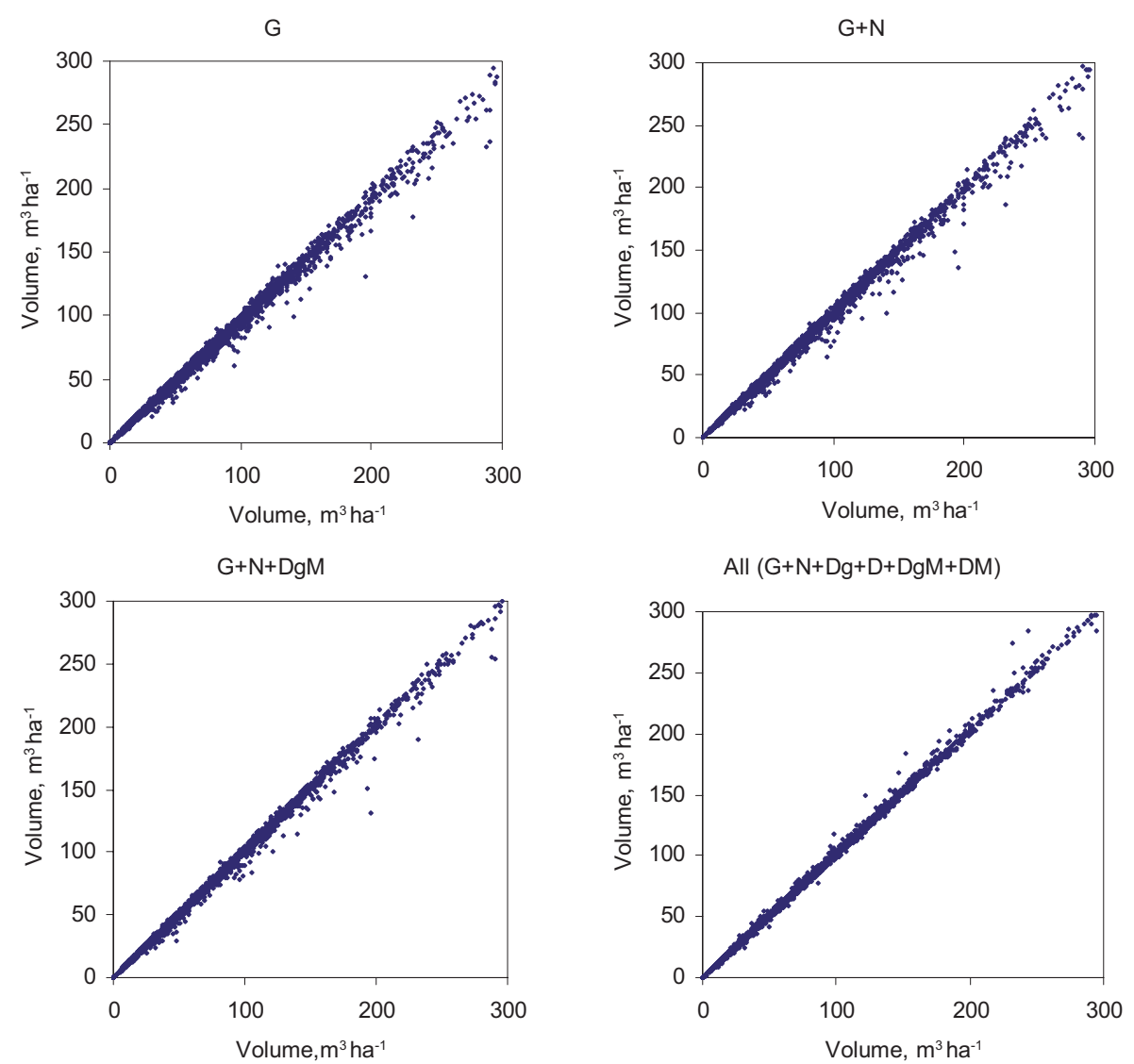

Figure 3. Stand volume of inventory plots estimated by four different methods to derive diameter distribution ( $y$ axis) versus the volume estimate based on measured trees ( $x$ axis).

Table IV. Root mean square error of different calibration methods for stand volume, predicted volume increment and optimal harvest. The RMSEs are calculated from the differences between estimates based on predicted diameter distributions and those based on measured distribution. In the RMSEs for cutting proposal, 'Cut in both' refers to stands having a cutting proposal with both the measured and predicted diameter distribution, and 'Cut with measured' to stands where there is a proposal with measured distribution.

\begin{tabular}{|c|c|c|c|c|}
\hline & $G(\operatorname{method} 1)$ & $G+N(\operatorname{method} 2)$ & $G+N+D g M(\operatorname{method} 3)$ & All (method 4) \\
\hline & \multicolumn{4}{|c|}{ Volume estimate } \\
\hline $\mathrm{m}^{3} \mathrm{ha}^{-1}$ & 8.3 & 5.4 & 3.9 & 4.2 \\
\hline \multirow[t]{2}{*}{$\%$ of mean } & 10.4 & 6.8 & 4.9 & 5.3 \\
\hline & \multicolumn{4}{|c|}{ 10-year growth prediction } \\
\hline $\mathrm{m}^{3} \mathrm{ha}^{-1}$ & 5.9 & 4.6 & 2.8 & 1.8 \\
\hline \multirow[t]{2}{*}{$\%$ of mean } & 26.3 & 20.5 & 12.5 & 8.3 \\
\hline & \multicolumn{4}{|c|}{ 10-year harvest } \\
\hline All stands, $\mathrm{m}^{3} \mathrm{ha}^{-1}$ & 30.0 & 30.8 & 29.0 & 28.1 \\
\hline All stands, $\%$ of mean & 149.0 & 152.7 & 143.9 & 139.3 \\
\hline Cut in both, $\mathrm{m}^{3} \mathrm{ha}^{-1}$ & 42.3 & 46.6 & 43.3 & 39.1 \\
\hline Cut in both, $\%$ of mean & 34.7 & 38.2 & 35.5 & 32.0 \\
\hline Cut with measured, $\mathrm{m}^{3} \mathrm{ha}^{-1}$ & 46.8 & 49.6 & 46.5 & 44.8 \\
\hline Cut with measured, $\%$ of mean & 59.9 & 63.3 & 59.5 & 57.4 \\
\hline
\end{tabular}


Table V. Similarity of cutting proposal in plans based on different input data. The number of plots in which there is a cutting proposal or no cutting proposal with both methods (measured diameter distribution and predicted distribution) are considered correct (boldface). The last line is the percentage of plots in which the difference in the proposed cutting volume is less than $10 \mathrm{~m}^{3} \mathrm{ha}^{-1}$.

\begin{tabular}{|c|c|c|c|c|c|c|c|c|}
\hline & \multicolumn{2}{|c|}{$G$} & \multicolumn{2}{|c|}{$G+N$} & \multicolumn{2}{|c|}{$G+N+D g M$} & \multicolumn{2}{|c|}{ All } \\
\hline & Cut & No cut & Cut & No cut & Cut & No cut & Cut & No cut \\
\hline Cut with measured & 411 & 230 & 416 & 225 & 439 & 202 & 435 & 206 \\
\hline$\%$ correct & \multicolumn{2}{|c|}{84.1} & \multicolumn{2}{|c|}{84.5} & \multicolumn{2}{|c|}{85.7} & \multicolumn{2}{|c|}{86.5} \\
\hline
\end{tabular}

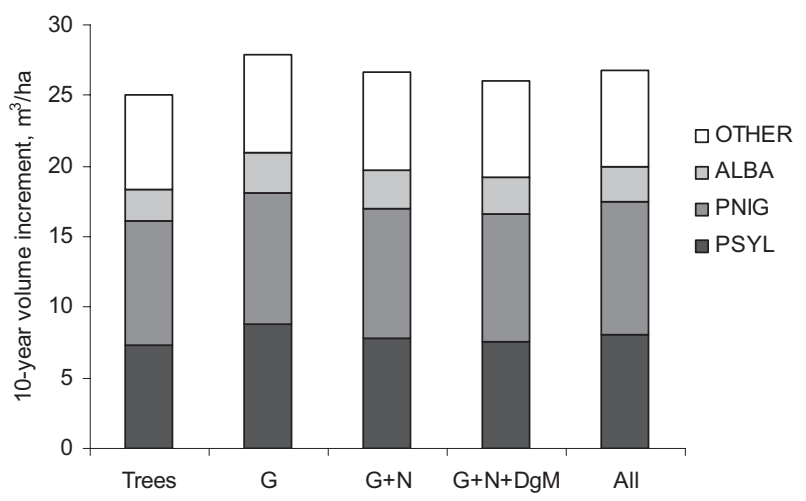

Figure 4. Mean 10-year volume growth based on the five different methods to use inventory data. The three most common species $(\mathrm{Pi}$ nus sylvestris, $P$. nigra and Abies alba) are shown individually.

proposal (cutting vs. no cutting) and the removal are the same. The number of such plots is the highest when all calibration variables were used. The relative RMSEs for removals are high, 139.9-152.7\% of the mean removal (Tab. IV), because differences arise both from different proposals and different cutting intensities. If only those plots are considered in which there is a cutting proposal with both input data alternatives the RMSE is $32-38 \%$ of the mean proposal. If differences in the proposed thinning intensity are ignored, stand level inventory data produced a cutting proposal similar to tree-level data in $84.1-86.5 \%$ of plots (Tab. V). The similarity is $70.9-75.7 \%$ if the harvested volumes may not differ more than $10 \mathrm{~m}^{3} \mathrm{ha}^{-1}$. Calibration of predicted distribution decreased discrepancies in cutting proposals.

\section{DISCUSSION}

In Catalonia, forest inventory is the most expensive task of forest management planning. Usually, many circular, concentric or relascope plots are placed within the stand and the diameters of individual trees of the plots are measured and recorded. This study shows that cheaper forest inventory methods could also be used with only some stand characteristics assessed in each stand. This can be done using so-called ocular stand inventory, which is the prevailing practice for instance in Finland [5]. Only a few measurements are taken, most of them being relascope counts of stand basal area. Small fixedarea plots may be used to count the number of trees per plot which is then converted into number of trees per hectare. The surveyor subjectively selects the places were measurements are taken. The reason of using this kind of ocular inventory is its cost effectiveness as compared to the measurement of individual trees on inventory plots.

This study showed that the outcome of forest planning calculations is rather similar if the analyses are based of measured trees or field-assessed stand-level variables. When there are many stands or plots with nearly similar characteristics, and the cutting target is such that only part of the stands are thinned or regenerated, the selection of the cut stands is rather sensitive to the inventory data. In the present study, this sensitivity was reflected so that the cutting proposals of plots differed in $15 \%$ of plots when tree level inventory data were changed into stand level data. If both the proposal (cut vs. not cut) and the harvested volume are considered the proposals differed in 25$30 \%$ of stands. However, the practical significance of these changes may be rather small since several treatment alternatives of the same stand may be nearly equally good.

The results suggest that stand-level variables could be assessed also in Catalonia when collecting field-data for forest planning, enabling savings in field inventory. However, the precision of the inventory also affects the choice. This study assumed that there was no sampling error or bias in the field data. In practice, both methods, measurement of individual trees on sample plots and assessing stand characteristics, contain sampling error. In addition, especially the ocular stand inventory is prone to bias, which depends on the way the surveyor places the plots and assesses the characteristics. It is hard to know without further studies which of the two methods would be more accurate in Catalonian conditions. Taking into account that most stands are rather heterogeneous it can be concluded that the sampling error of plot inventory is rather large.

If the precision of field-assessed stand variables is known when stand level data are used, it can be taken into account when calibrating the predicted diameter distributions. The precision of the predicted Weibull distributions can also be taken into account. Mehtätalo [5] and Palahí et al. [11] discuss methods to do this. 

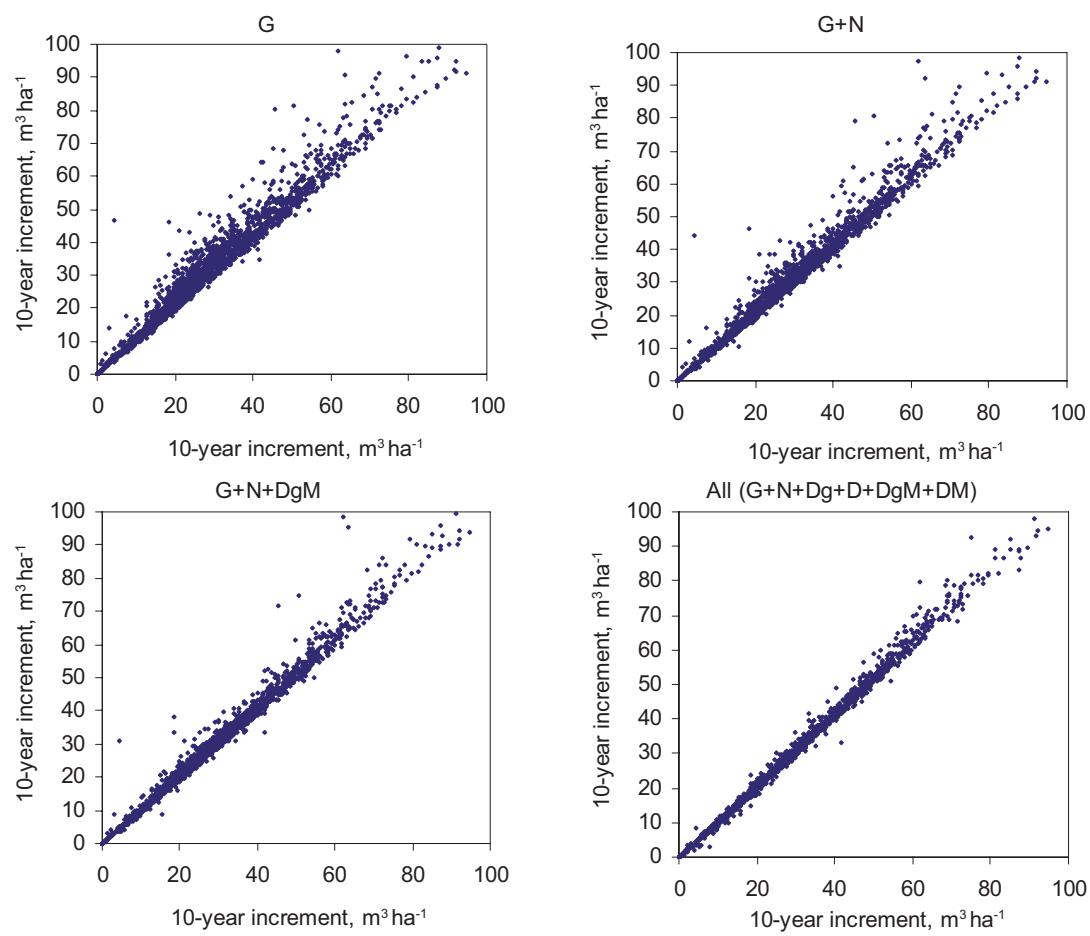

Figure 5. Ten-year volume growth predictions based on four different methods to derive diameter distribution ( $y$ axis) versus the 10-year volume growth estimate based on measured trees ( $x$ axis).
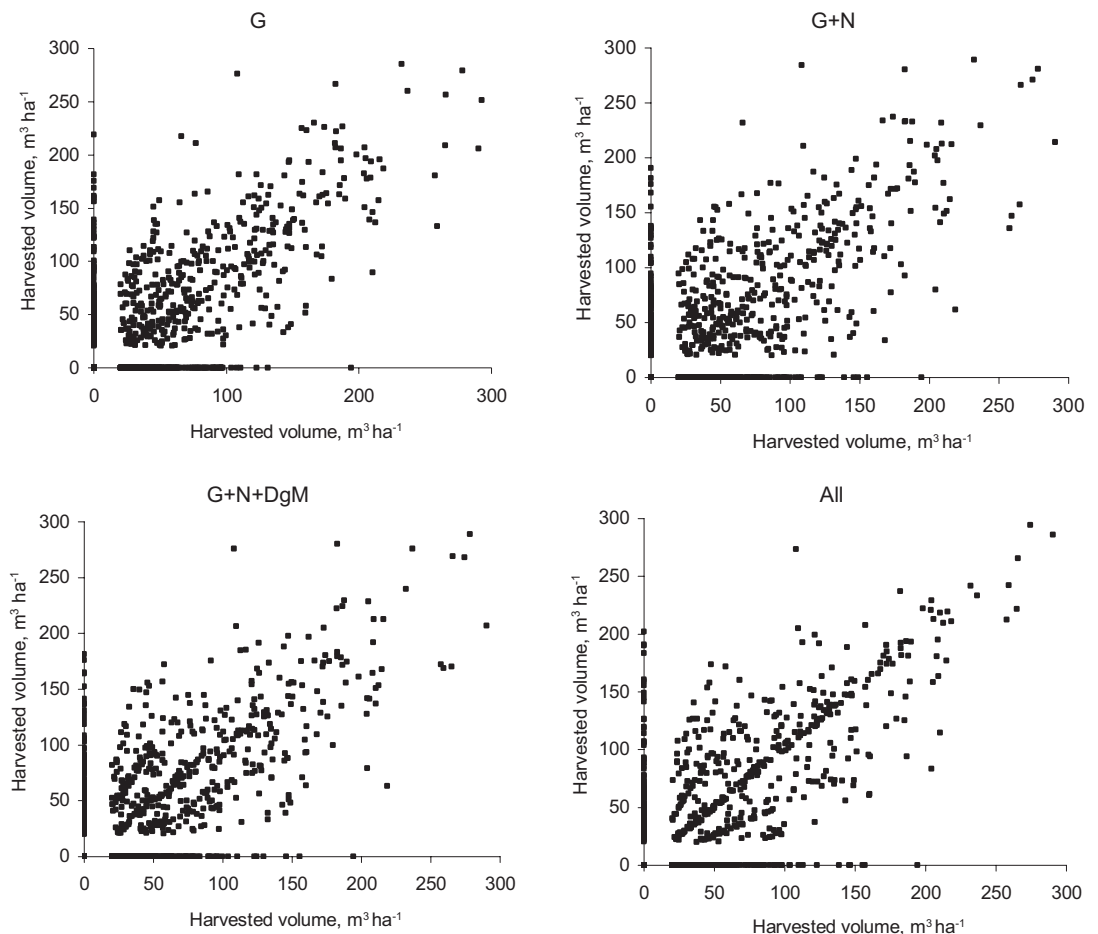

Figure 6. Optimal harvested volumes for the coming 10-year period when measured ( $x$ axis) or predicted ( $y$ axis) diameter distributions were used as input data. Net income and the annual value increment of the remaining growing stock were maximized subject to $5 \mathrm{million}^{3}$ harvesting target during the 10 -year planning period. 
The present study developed new parameter prediction models for basal area diameter distribution for several main tree species in Catalonia. In mixed stands, the diameter distributions were estimated by tree species [4]. Based on the study on Palahí et al. [12], which compared several probability density functions, the truncated Weibull function was selected to model the diameter distribution of stand basal area.

The models were based on permanent sample plots included in the Spanish National Forest Inventory. This sample provided a good database in terms of size and forest conditions. The parameter prediction models developed enable one to predict the basal area diameter distribution for any forest stand in Catalonia using rather limited information $(G, N$, or $D q$ and $E$ ). The predicted diameter distribution can be divided into diameter classes and their centre points can be used as representative trees. Then, tree-wise growth models can be used to predict stand development under different management parameters.

This study tested the effect of different methods to derive the diameter distribution from inventory data in forest planning calculations. The methods were compared in terms of the growing stock volume estimate, growth predictions and optimal harvests. The main conclusion of the analyses is that the use of stand level inventory data together with predicted diameter distributions gives very similar inventory results and management plans as the use of tree level inventory data. Calibration of the predicted diameter distribution of trees improved the accuracy of the calculations. The more there were calibration variables, i.e., the more stand variables are assessed in the field, the better are the calculation results. However, the use three calibration variables $(G+N+D g M)$ performed practically equally well as the use of six calibration variables. Therefore, using $G, N$ and $D g M$ to calibrate the predicted diameter distribution can be considered a sufficient method in forest planning calculations. Instead of $D g M$ (basal area median diameter), basal-area-weighted mean diameter may also be used [10].

A recent study by Kangas and Maltamo [3], which examined the effect of calibration on growth predictions, showed results similar to the ones obtained in this study. In addition, Kangas and Maltamo [3] found that the effect of calibration was clearer in heavily thinned stands than in untreated ones.

Some of the differences in the harvested volume calculations were partly because of a random component; heuristics were used in optimization, and they were based on inspecting "random moves". In two nearly similar stands (A and B), one optimization run may have selected for instance a heavy thinning to stand $\mathrm{A}$ and medium intensity thinning in stand $\mathrm{B}$ but a second run could have done the opposite. Therefore, a more careful optimization and fewer treatment alternatives per stand would have reduced the differences.

Acknowledgements: This study has been conducted within the research project AGL2004-00382 funded by the Ministerio de Educación y Ciencia of Spain, Secretaria de Política Científica y Tecnológica.

\section{REFERENCES}

[1] Cao, Predicting parameters of a Weibull function for modelling diameter distribution, For. Sci. 50 (2004) 682-685.

[2] ICONA, Segundo Inventario Forestal Nacional (1986-1995) Cataluña: Barcelona, Girona, Lleida and tarragona. MAPA, Madrid, 1993.

[3] Kangas A., Maltamo M., Calibrating predicted diameter distribution with additional information in growth and yield predictions, Can. J. For. Res. 33 (2003) 430-434.

[4] Maltamo M., Comparing basal area diameter distributions estimated by tree species and for the entire growing stock in a mixed stand, Silva Fenn. 31 (1997) 53-65.

[5] Mehtätalo L., An algorithm for ensuring the compatibility between estimated percentiles of diameter dirtribution and measured stand variables, For. Sci. 50 (2004) 20-32.

[6] Palahí M., Modelling stand development and optimising the management of even-aged Scots pine forests in north-east Spain. Academic Dissertation. Research notes 143. Faculty of Forestry, University of Joensuu, 2002.

[7] Palahí M., Pukkala T., Aplicación de métodos heurísticos en la resolución de problemas de planificación forestal, Actas de la reunión de modelización forestal, Cuadernos de la sociedad de ciencias forestales españolas, Núm. 18 (2004) 103-109.

[8] Palahí M., Pukkala T., Miina J., Montero G., Individual-tree growth and mortality models for Scots pine (Pinus sylvestris L.) in northeast Spain, Ann. For. Sci. 60 (2003) 1-10.

[9] Palahí M., Grau Corbí J., Preliminary site index model and individual-tree growth and mortality models for Black pine (Pinus nigra Arn.) in Catalonia (Spain). Invest. Agr.: Sist. Recur. For. 12 (2003) 137-148.

[10] Palahí M., Pukkala T., Trasobares A., Modelling the diameter distribution of Pinus sylvestris, Pinus nigra and Pinus halepensis forest stands in Catalonia using the truncated Weibull function, Forestry 79 (2006) 553-562.

[11] Palahí M., Pukkala T., Trasobares A., Calibrating predicted tree diameter distributions in Catalonia (Spain), Silva Fenn. 40 (2006) 487-500.

[12] Palahí M., Pukkala T., Blasco E., Trasobares A., Comparison of Beta, Johnson's SB, Weibull and truncated Weibull functions for modelling the diameter distribution of forest stands in Catalonia (north-east of Spain), Eur. J. For. Res. 126 (2007) 563-571.

[13] Pukkala T., MONTE, Calculation and Planning Program for Even-Aged and Uneven-Aged Forests of Catalonia, User's guide, Joensuu, 2003.

[14] Reeves C.R. (Ed.), Modern heuristic techniques for combinatorial problems, John Wiley \& Sons, Inc., New York, 1993, 320 p.

[15] Trasobares A., Modelling and management of uneven-aged pine forests in Catalonia, north-east Spain, Academic Dissertation, University of Joensuu, Faculty of Forestry, Research Notes 155, 2003.

[16] Trasobares A., Pukkala T., Using past growth to improve individualtree diameter growth models for uneven-aged mixtures of Pinus sylvestris L. and Pinus nigra Arn. in Catalonia, north-east Spain, Ann. For. Sci. 61 (2004) 409-417.

[17] Trasobares A., Pukkala T., Miina J., Growth and yield model for uneven-aged mixtures of Pinus sylvestris L. and Pinus nigra Arn. in Catalonia, north-east Spain, Ann. For. Sci. 61 (2004) 9-24.

[18] Trasobares A., Tomé M., Miina J., Growth and yield model for Pinus halepensis Mill. in Catalonia, north-east Spain, For. Ecol. Manage. 203 (2004) 49-62. 